\title{
Evaluation of the Results of Group B Streptococcus Screening by MALDI-TOF MS among Pregnant Women in a Hungarian Hospital
}

\author{
Marianna Ábrók ${ }^{1, * \mathbb{C}}$, Petra Tigyi ${ }^{1}$, Markus Kostrzewa ${ }^{2}$, Katalin Burián ${ }^{1}$ and Judit Deák ${ }^{1}$ \\ 1 Institute of Clinical Microbiology, Albert Szent-Györgyi Clinical Center, University of Szeged, \\ 6725 Szeged, Hungary \\ 2 Bioanalytical Development, Bruker Daltonik GmbH, 28359 Bremen, Germany \\ * Correspondence: mpabrok@gmail.com; Tel.: +36-62-545399
}

Received: 2 December 2019; Accepted: 15 December 2019; Published: 18 December 2019

\begin{abstract}
Pregnant women colonized by Streptococcus agalactiae, or group B streptococcus (GBS), are at an increased risk of premature delivery and stillbirth, and their neonates can be endangered by the development of an invasive GBS disease. In this study, the results of the GBS screening among pregnant women performed between 2012 and $2018(n=19267)$ are presented. For the GBS positive samples, the antibiotic susceptibility of the isolated strains was also tested $(n=3554)$. During the examined period, the colonization rate varied between $17.4 \%$ and $19.8 \%$. The overall rate of erythromycin and clindamycin resistance in the GBS positive samples was $34.9 \%$ and $34.6 \%$, respectively. The frequency of the erythromycin and clindamycin resistant strains showed an increasing tendency. An analysis of the MALDI-TOF MS spectra of 260 GBS isolates revealed that $46.5 \%$ of them belonged to either the ST- 1 or the ST- 17 sequence types, indicating a high prevalence of these potentially invasive GBS strains in our region. More than half of the strains identified as ST-1 (52.1\%) proved to be resistant to erythromycin and clindamycin.
\end{abstract}

Keywords: Streptococcus agalactiae; antibiotic susceptibility; ST-1; ST-17; MALDI-TOF MS

\section{Introduction}

Streptococcus agalactiae (S. agalactiae), also known as group B streptococcus (GBS), may cause serious infections in newborns, pregnant and postpartum women, and immunocompromised adults $[1,2]$. This Gram-positive $\beta$-haemolytic bacterium can cause urinary tract infections, fever, chorioamnionitis, endometritis, and puerperal sepsis in women [3-5], and it is among the leading causes of neonatal invasive diseases in the United States and Europe [5-8]. Approximately $10 \%-30 \%$ of pregnant women are colonized by GBS without any symptoms $[6,9,10]$. However, these women are at an increased risk of premature delivery and stillbirth, and their newborns can be exposed to the development of an invasive GBS disease [2,5]. Therefore, vaginal or rectal GBS colonization indicates intrapartum antibiotic prophylaxis. Matrix-assisted laser desorption/ionization time-of-flight mass spectrometry (MALDI-TOF MS) is an effective method for the identification of GBS strains at the species level [11,12]. Moreover, MALDI-TOF MS also proven to be applicable to detect the $S$. agalactiae sequence types ST-17 and ST-1 based on the characteristic peak-shifts present in their protein MS spectra [13]. Within S. agalactiae, various sequence types could be discerned by the multi locus sequence typing (MLST) method [11]. Among these MLST types, ST-17 is considered as highly virulent, and was found to be one of the most frequent agents of neonatal meningitis and GBS late-onset-disease (LOD) [13-15]. Furthermore, ST-1 has become another significant cause of invasive neonatal infections, since its emergence in the 1990s $[13,15,16]$. 
The aim of the present study was to analyze the results of the GBS screening among pregnant women and antibiotic susceptibility testing at the Albert Szent-Györgyi Clinical Center (University of Szeged, Hungary) between 2012 and 2018. We also report our experiences in the application of the rapid MALDI-TOF MS-based detection of ST-17 and ST-1 GBS.

\section{Results}

\subsection{Colonization}

During the examined period, vaginal or cervical samples of 19,267 pregnant women were screened for S. agalactiae, among which 3554 samples proved to be GBS positive (Table 1). The colonization rate showed only slight changes in the various years, and its value fluctuated between $17.4 \%$ and $19.8 \%$ (the mean value is $18.4 \%$ ). Although much less samples (3566) were tested in the age group of 26-30 years than those (6510) in the age group of 31-35 years, the colonization rate was the same in both groups $(19 \%)$, which was the highest rate compared with the other age groups (Table 1). At the same time, the colonization rate was higher than $10 \%$ in each age group.

Table 1. Number of screened and the group B streptococcus (GBS) positive samples and the colonization rates measured in the different age groups during the examined period.

\begin{tabular}{|c|c|c|c|c|c|c|c|c|c|}
\hline \multicolumn{2}{|c|}{ Age Groups (Years Old) } & $<21$ & $21-25$ & $26-30$ & $31-35$ & $36-40$ & $41-45$ & $>45$ & Total \\
\hline \multicolumn{10}{|l|}{ Year } \\
\hline \multirow[t]{3}{*}{2012} & No. of screened samples & 4 & 73 & 468 & 1037 & 823 & 357 & 114 & 2876 \\
\hline & No. of GBS positive samples & 0 & 10 & 80 & 196 & 150 & 53 & 17 & 506 \\
\hline & (colonization rate; $\%$ ) & $(0)$ & $(13.7)$ & $(17.1)$ & $(18.9)$ & $(18.2)$ & $(14.8)$ & $(14.9)$ & $(17.6)$ \\
\hline \multirow[t]{3}{*}{2013} & No. of screened samples & 6 & 88 & 538 & 966 & 867 & 329 & 116 & 2910 \\
\hline & No. of GBS positive samples & 1 & 24 & 96 & 176 & 142 & 52 & 17 & 508 \\
\hline & (colonization rate; \%) & $(16.7)$ & $(27.3)$ & $(17.8)$ & $(18.2)$ & $(16.4)$ & $(15.8)$ & $(14.7)$ & $(17.5)$ \\
\hline \multirow[t]{3}{*}{2014} & No. of screened samples & 10 & 94 & 539 & 1015 & 890 & 344 & 115 & 3007 \\
\hline & No. of GBS positive samples & 2 & 15 & 106 & 212 & 168 & 69 & 23 & 595 \\
\hline & (colonization rate; \%) & $(20.0)$ & $(16.0)$ & $(19.7)$ & $(20.9)$ & $(18.9)$ & $(20.1)$ & $(20.0)$ & $(19.8)$ \\
\hline \multirow[t]{3}{*}{2015} & No. of screened samples & 3 & 103 & 557 & 992 & 884 & 352 & 89 & 2980 \\
\hline & No. of GBS positive samples & 0 & 16 & 101 & 198 & 177 & 67 & 17 & 576 \\
\hline & (colonization rate; \%) & $(0)$ & $(15.5)$ & $(18.1)$ & $(20.0)$ & $(20.0)$ & $(19.0)$ & $(19.1)$ & $(19.3)$ \\
\hline \multirow[t]{3}{*}{2016} & No. of screened samples & 9 & 92 & 568 & 1001 & 866 & 341 & 89 & 2966 \\
\hline & No. of GBS positive samples & 2 & 17 & 123 & 193 & 160 & 57 & 18 & 570 \\
\hline & (colonization rate; \%) & $(22.2)$ & $(18.5)$ & $(21.7)$ & $(19.3)$ & $(18.5)$ & $(16.7)$ & $(20.2)$ & $(19.2)$ \\
\hline \multirow[t]{3}{*}{2017} & No. of screened samples & 7 & 108 & 584 & 951 & 839 & 331 & 60 & 2880 \\
\hline & No. of GBS positive samples & 1 & 14 & 111 & 158 & 147 & 62 & 9 & 502 \\
\hline & (colonization rate; \%) & $(14.3)$ & $(13.0)$ & $(19.0)$ & $(16.6)$ & $(17.5)$ & $(18.7)$ & $(15.0)$ & $(17.4)$ \\
\hline \multirow[t]{3}{*}{2018} & No. of screened samples & 3 & 75 & 312 & 548 & 480 & 197 & 33 & 1648 \\
\hline & No. of GBS positive samples & 0 & 13 & 59 & 109 & 85 & 27 & 4 & 297 \\
\hline & (colonization rate; \%) & (0) & $(17.3)$ & $(18.9)$ & $(19.9)$ & $(17.7)$ & $(13.7)$ & $(12.0)$ & $(18.0)$ \\
\hline \multirow[t]{3}{*}{ Total } & No. of screened samples & 42 & 633 & 3566 & 6510 & 5649 & 2251 & 616 & 19267 \\
\hline & No. of GBS positive samples & 6 & 109 & 676 & 1242 & 1029 & 387 & 105 & 3554 \\
\hline & (colonization rate; \%) & $(14.3)$ & $(17.2)$ & $(19.0)$ & $(19.0)$ & $(18.2)$ & $(17.2)$ & $(17.1)$ & $(18.5)$ \\
\hline
\end{tabular}

\subsection{Antimicrobial Susceptibility Testing}

In the case of the 3554 GBS positive samples, the susceptibility of the isolated strains to penicillin, cefuroxime, vancomycin, erythromycin, clindamycin, and trimethoprim-sulfamethoxazole was also tested. All of the tested strains proved to be susceptible to beta-lactams (i.e., penicillin and cefuroxime), vancomycin, and trimethoprim-sulfamethoxazole. The overall frequency of the erythromycin and clindamycin resistant isolates were $34.9 \%$ and $34.6 \%$, respectively, while co-resistance to the two 
antibiotics was detected in $33.2 \%$ of the GBS positive samples (Table 2). However, between the years 2012 and 2018, the frequency of the erythromycin and clindamycin resistant GBS strains increased from $29.2 \%$ and $30.2 \%$ to $39.7 \%$ and $38.7 \%$, respectively, while the co-resistance level increased from $28 \%$ to $35.7 \%$ (Table 2). Only a low percentage of the isolated strains proved to be resistant to either erythromycin or clindamycin alone (i.e., $1.9 \%$ and $1.4 \%$, respectively) (Table 2). Inducible clindamycin resistance was detected only in $6.5 \%$ of the isolated GBS strains.

Table 2. Number and proportion of erythromycin and clindamycin resistant strains isolated from the GBS positive samples.

\begin{tabular}{ccccccc}
\hline Year & $\begin{array}{c}\text { GBS } \\
\text { Positive } \\
\text { Samples }\end{array}$ & $\begin{array}{c}\text { Erythromycin } \\
\text { Resistant } \\
\text { Strains (\%) }\end{array}$ & $\begin{array}{c}\text { Clindamycin } \\
\text { Resistant } \\
\text { Strains (\%) }\end{array}$ & $\begin{array}{c}\text { Strains Resistant } \\
\text { to Erythromycin } \\
\text { Alone (\%) }\end{array}$ & $\begin{array}{c}\text { Strains Resistant } \\
\text { to Clindamycin } \\
\text { Alone (\%) }\end{array}$ & $\begin{array}{c}\text { Erythromycin- } \\
\text { Clindamycin } \\
\text { Co-Resistant Strains (\%) }\end{array}$ \\
\hline 2012 & 506 & $148(29.2)$ & $153(30.2)$ & $6(1.2)$ & $11(2.2)$ & $142(28)$ \\
2013 & 508 & $172(33.9)$ & $170(33.5)$ & $6(1.2)$ & $4(0.8)$ & $166(32.8)$ \\
2014 & 595 & $190(31.9)$ & $182(30.6)$ & $17(2.9)$ & $9(1.5)$ & $173(29.1)$ \\
2015 & 576 & $222(38.5)$ & $221(38.4)$ & $11(1.9)$ & $10(1.7)$ & $211(36.6)$ \\
2016 & 570 & $196(34.4)$ & $182(31.9)$ & $14(2.5)$ & $6(0)$ & $182(31.9)$ \\
2017 & 502 & $206(41.0)$ & $206(41.0)$ & $6(1.2)$ & $9(3.0)$ & $200(39.8)$ \\
2018 & 297 & $118(39.7)$ & $115(38.7)$ & $12(4.0)$ & $49(1.4)$ & $106(35.7)$ \\
Total & 3554 & $1239(34.9)$ & $1230(34.6)$ & $68(1.9)$ & & $1181(33.2)$ \\
\hline
\end{tabular}

\subsection{ST-1 and ST-17 Detection}

The presence of the protein peaks characteristic of the highly virulent invasive ST-1 and ST-17 clones was examined in the MS spectra of 260 randomly selected GBS strains isolated in 2017 and 2018. According to this analysis, 27.3\% (71 strains) of the tested strains belonged to the ST-1 type, and 19.2\% (50 strains) proved to be ST-17 (Table 3). While the proportion of the erythromycin and clindamycin co-resistant ST-17 strains (32\%) did not differ significantly from that of the non-ST-1 and non-ST-17 strains (30.9\%), 52.1\% of the 71 ST-1 strains proved to be resistant to both antibiotics (Table 3). Moreover, all of these ST-1 strains were co-resistant to erythromycin and clindamycin. At the same time, $2 \%$ and $2.9 \%$ of the ST-17 and the non-ST-1 and non-ST-17 strains, respectively, proved to be resistant to clindamycin alone. The proportion of strains with induced clindamycin resistance was $4 \%$ (two strains) for the ST-17, 5.6\% (four strains) for the ST-1, and 7.9\% (eleven strains) for the non-ST-1 and non-ST-17 strains. Erythromycin resistance alone was not detected among the 260 tested strains.

Table 3. Number and rate of the ST-1 and ST-17 strains detected by the analysis of the matrix-assisted laser desorption/ionization time-of-flight mass spectrometry (MALDI-TOF MS) spectra, and the number and rate of the erythromycin and clindamycin resistant strains among them.

\begin{tabular}{lccccc}
\hline \multicolumn{1}{c}{ Sequence Type } & $\begin{array}{c}\text { No. of } \\
\text { Strains } \\
\text { Detected (\%) }\end{array}$ & $\begin{array}{c}\text { Erythromycin } \\
\text { Resistant } \\
\text { Strains (\%) }\end{array}$ & $\begin{array}{c}\text { Clindamycin } \\
\text { Resistant } \\
\text { Strains (\%) }\end{array}$ & $\begin{array}{c}\text { Strains Resistant } \\
\text { to Clindamycin } \\
\text { Alone (\%) }\end{array}$ & $\begin{array}{c}\text { Erythromycin- } \\
\text { Clindamycin } \\
\text { Co-Resistant Strains (\%) }\end{array}$ \\
\hline $\begin{array}{l}\text { ST-1 } \\
\text { ST-17 }\end{array}$ & $71(27.3)$ & $37(52.1)$ & $37(52.1)$ & $0(0)$ & $37(52.1)$ \\
$\begin{array}{l}\text { Other } \\
\text { (non-ST-1, non-ST-17) }\end{array}$ & $139(19.2)$ & $16(32.0)$ & $17(34.0)$ & $1(2.0)$ & $16(32.0)$ \\
\hline
\end{tabular}

\section{Discussion}

In our study, the GBS colonization level was found to be around $20 \%$ during the examined period. This value falls into the range of the colonization rates (i.e., from $6.5 \%$ to $36 \%$ ) reported earlier for European countries $[15,17]$, but it is somewhat higher than that reported recently in the neighboring country, Serbia (15\%) [18]. At the same time, this relatively high colonization rate emphasizes the importance of the accurate GBS screening of pregnant women.

All of the GBS strains were susceptible to beta-lactams and vancomycin, which can be considered as a common pattern observed in several previous studies [19-22]. At the same time, a high 
level of resistance to erythromycin and clindamycin, and a clearly increasing tendency in the frequency of resistant strains has been observed over the years examined. Other studies have also reported the spreading of macrolide and lincosamide resistance among the GBS strains [23-25], and highlighted the need of susceptibility testing of colonizing GBS strains for an effective intrapartum antibiotic prophylaxis [10-26]. The majority of erythromycin and clindamycin resistant strains proved to be co-resistant to these antibiotics, and the majority of the detected clindamycin resistances were constitutive.

The method of Lartigue et al. [13] was used for the MALDI-TOF MS-based detection of the ST-17 and ST-1 strains. These GBS sequence types have frequently been associated with neonatal meningitis and invasive neonatal infections [15]. In our study, almost half (46.5\%) of the examined S. agalactiae strains proved to be either ST-1 (27.3\%) or ST-17 (19.2\%) clones, indicating a high prevalence of these potentially virulent and invasive GBS strains in our region. It should be mentioned that, according to Lartigue et al. [13], the sensitivity and specificity of this identification method were $100 \%$ and $95 \%$, respectively, for ST-1, and $100 \%$ and $98 \%$, respectively, for ST- 17 .

ST-1 is thought to be the predominant colonizer in pregnant women, and found to be one of the most frequent clones in vaginal samples $[15,27,28]$. Our study also indicates a significant distribution of the ST-17 clone. Recently, Gajic et al. [18] found this sequence type as the most common clone in Serbian samples. Moreover, the rate of erythromycin and clindamycin co-resistance was found to be extremely high among the ST-1 clones (52.1\%). Previously, Bergseng et al. [16] also found a strong association of ST-1 clones and erythromycin resistance.

To our knowledge, this study is the first analysis of the GBS screening results and the antibiotic susceptibility pattern of GBS strains colonizing pregnant women in our region, and the first data about the frequency of highly virulent ST-1 and ST-17 GBS clones in Hungary.

Our work demonstrates the value and usefulness of MALDI-TOF MS analysis in GBS screening, and reinforces that the examination of the MALDI-TOF MS spectra is a useful method to detect the potentially invasive ST-1 and ST-17 GBS clones. The high frequency of these clones in our samples indicates the importance of the accurate $S$. agalactiae screening of pregnant women, because almost half of GBS-positive pregnant women can be colonized by these highly virulent clones in our region.

\section{Materials and Methods}

\subsection{Research Design and Samples}

The study was conducted in the Albert Szent-Györgyi Clinical Center (University of Szeged, Hungary), and was approved by the institutional review board (no. 197/2017-SZTE). GBS screenings were performed on vaginal or cervical samples of all of the pregnant women aged from 14 to 58 years $(n=19,267)$ who attended at the clinical center to detect their GBS colonization status from January 2012 to July 2018. For each GBS positive sample, antibiotic susceptibility of the isolated GBS strain was tested $(n=3554)$. From the strains isolated from January 2017 to July 2018, 260 isolates were randomly selected and subjected to ST-1 and ST-17 detection.

\subsection{GBS Screening of Pregnant Women}

GBS screening was performed according to the CDC 2010 guideline [10] in each case. Samples were inoculated onto Columbia agar plates containing $5 \%$ sheep blood (bioMérieux, France), and incubated at $35-37^{\circ} \mathrm{C}$ in $5 \% \mathrm{CO}_{2}$. In parallel, a selective enrichment was also performed in modified Todd Hewitt broth (OXOID, England) supplemented with nalidixic acid $(0.015 \mathrm{~g} / \mathrm{L})$ and colistin $(0.010 \mathrm{~g} / \mathrm{L})$ at $35-37^{\circ} \mathrm{C}$ in $5 \% \mathrm{CO}_{2}$. After incubation for $18-24 \mathrm{~h}$, the enriched broth was plated onto CHROMagar StrepB (CHROMagar, France) and subcultured at $37^{\circ} \mathrm{C}$ under aerobic conditions for 18,24 , or $48 \mathrm{~h}$. After incubation, the Columbia agar or CHROMagar StrepB plates were inspected to detect suspicious colonies. The presumptive GBS colonies were identified by MALDI-TOF MS or by traditional methods 
(i.e., colony morphology, beta-haemolysis, bacitracin resistance, CAMP test, and Lancefield-group B detection by latex agglutination test with Pastorex Strep Kit [Bio-Rad, France]).

\subsection{MALDI-TOF MS Analysis}

For the species level identification of the isolated bacterial colonies, a MALDI-TOF MS analysis was performed using a MALDI Biotyper system (Bruker Daltonik GmbH, Germany) in the positive linear mode across the $\mathrm{m} / \mathrm{z}$ range of 2 to $20 \mathrm{kDa}$. For each spectrum, 240 laser shots at $60 \mathrm{~Hz}$ in groups of 40 shots per sampling area were collected. The spectra were analyzed by the MALDI Biotyper RTC 3.1 software (Bruker Daltonics, Germany), using the MALDI Biotyper Library 3.1. The ST-1 and ST-17 sequence types were identified by examining the MS spectra of the selected strains and detecting the presence of the 6250-Da protein specific to ST-1 or the 7625-Da protein specific to ST-17, according to the method described by Lartigue et al. [13].

\subsection{Antibiotic Susceptibility Testing}

Antimicrobial susceptibility was tested to penicillin, cefuroxime, vancomycin, trimethoprimsulfamethoxazole, erythromycin, and clindamycin. The testing was performed by the disk diffusion method, according to the recommendations of The European Committee on Antimicrobial Susceptibility Testing (EUCAST) (http://www.eucast.org/; [29]).

Author Contributions: Conceptualization, M.Á.; methodology, M.Á. and M.K.; investigation, M.Á., P.T., and M.K.; resources, M.Á., J.D., and K.B.; writing (original draft preparation), M.Á.; writing (review and editing), M.Á., M.K., K.B., and J.D; supervision, J.D. All authors have read and agreed to the published version of the manuscript.

Funding: This research received no external funding.

Acknowledgments: The authors would like to thank Elisabeth Nagy for her valuable suggestions that helped to improve the manuscript.

Conflicts of Interest: The authors declare no conflict of interest. M.K. is an employee of Bruker Daltonik GmbH, the manufacturer of the MALDI Biotyper.

\section{References}

1. Le Doare, K.; Heath, P.T. An overview of global GBS epidemiology. Vaccine 2013, 31, D7-D12. [CrossRef]

2. Furfaro, L.L.; Chang, B.J.; Payne, M.S. Perinatal Streptococcus agalactiae epidemiology and surveillance targets. Clin. Microbiol. Rev. 2018, 31. [CrossRef]

3. Baker, C. Group B streptococcal infections. In Streptococcal Infections; Stevens, D.L., Kaplan, E.L., Eds.; Oxford University Press: New York, NY, USA, 2000; pp. 222-237.

4. Schrag, S.J.; Zywicki, S.; Farley, M.M.; Reingold, A.L.; Harrison, L.H.; Lefkowitz, L.B.; Hadler, J.L.; Danila, R.; Cieslak, P.R.; Schuchat, A. Group B streptococcal disease in the era of intrapartum antibiotic prophylaxis. N. Engl. J. Med. 2000, 342, 15-20. [CrossRef]

5. Melin, P. Neonatal group B streptococcal disease: From pathogenesis to preventive strategies. Clin. Microbiol. Infect. 2011, 17, 1294-1303. [CrossRef] [PubMed]

6. Artz, L.A.; Kempf, V.A.; Autenrieth, I.B. Rapid screening for Streptococcus agalactiae in vaginal specimens of pregnant women by fluorescent in situ hybridization. J. Clin. Microbiol. 2003, 41, 2170-2173. [CrossRef] [PubMed]

7. Brimil, N.; Barthell, E.; Heindrichs, U.; Kuhn, M.; Lütticken, R.; Spellerberg, B. Epidemiology of Streptococcus agalactiae colonization in Germany. Int. J. Med. Microbiol. 2010, 296, 39-44. [CrossRef] [PubMed]

8. Jones, A.L.; Knoll, K.M.; Rubens, C.E. Identification of Streptococcus agalactiae virulence genes in the neonatal rat sepsis model using signature-tagged mutagenesis. Mol. Microbiol. 2000, 37, 1444-1455. [CrossRef]

9. Caliot, É.; Dramsi, S.; Chapot-Chartier, M.P.; Courtin, P.; Kulakauskas, S.; Péchoux, C.; Trieu-Cuot, P.; Mistou, M.Y. Role of the group B antigen of Streptococcus agalactiae: A peptidoglycan-anchored polysaccharide involved in cell wall biogenesis. PLoS Pathog. 2012, 8, e1002756. [CrossRef]

10. Centers for Disease Control and Prevention. Prevention of Perinatal Group B Streptococcal Disease, Revised Guidelines from CDC. MMWR 2010, 59, 1-36. 
11. Lartigue, M.F.; Héry-Arnaud, G.; Haguenoer, E.; Domelier, A.S.; Schmit, P.O.; van der Mee-Marquet, N.; Lanotte, P.; Mereghetti, L.; Kostrzewa, M.; Quentin, R. Identification of Streptococcus agalactiae isolates from various phylogenetic lineages by matrix-assisted laser desorption ionization-time of flight mass spectrometry. J. Clin. Microbiol. 2009, 47, 2284-2287. [CrossRef]

12. Cherkaoui, A.; Emonet, S.; Fernandez, J.; Schorderet, D.; Schrenzel, J. Evaluation of matrix-assisted laser desorption/ionization time-of-flight mass spectrometry for the rapid identification of beta-hemolytic streptococci. J. Clin. Microbiol. 2011, 49, 3004-3005. [CrossRef] [PubMed]

13. Lartigue, M.F.; Kostrzewa, M.; Salloum, M.; Haguenoer, E.; Héry-Arnaud, G.; Domelier, A.S.; Stumpf, S.; Quentin, R. Rapid detection of "highly virulent" Group B Streptococcus ST-17 and emerging ST-1 clones by MALDI-TOF mass spectrometry. J. Microbiol. Meth. 2011, 86, 262-265. [CrossRef] [PubMed]

14. Manning, S.D.; Springman, A.C.; Lehotzky, E.; Lewis, M.A.; Whittam, T.S.; Davies, H.D. Multilocus sequence types associated with neonatal group B streptococcal sepsis and meningitis in Canada. J. Clin. Microbiol. 2009, 47, 1143-1148. [CrossRef] [PubMed]

15. Shabayek, S.; Spellerberg, B. Group B streptococcal colonization, molecular characteristics, and epidemiology. Front. Microbiol. 2018, 9, 437. [CrossRef] [PubMed]

16. Bergseng, H.; Afset, J.E.; Radtke, A.; Loeseth, K.; Lyng, R.V.; Rygg, M.; Bergh, K. Molecular and phenotypic characterization of invasive group B streptococcus strains from infants in Norway 2006-2007. Clin. Microbiol. Infect. 2009, 15, 1182-1185. [CrossRef]

17. Barcaite, E.; Bartusevicius, A.; Tameliene, R.; Kliucinskas, M.; Maleckiene, L.; Nadisauskiene, R. Prevalence of maternal group B streptococcal colonisation in European countries. Acta Obstet. Gynecol. Scand. 2008, 87, 260-271. [CrossRef]

18. Gajic, I.; Plainvert, C.; Kekic, D.; Dmytruk, N.; Mijac, V.; Tazi, A.; Glaser, P.; Ranin, L.; Poyart, C.; Opavski, N. Molecular epidemiology of invasive and non-invasive group B Streptococcus circulating in Serbia. Int. J. Med. Microbiol. 2019, 309, 19-25. [CrossRef]

19. Garland, S.M.; Cottrill, E.; Markowski, L.; Pearce, C.; Clifford, V.; Ndisang, D.; Kelly, N.; Daley, A.J. Antimicrobial resistance in group B streptococcus: The Australian experience. J. Med. Microbiol. 2011, 60, 230-235. [CrossRef]

20. Nakamura, P.A.; Schuab, R.B.B.; Neves, F.P.; Pereira, C.F.; Paula, G.R.; Barros, R.R. Antimicrobial resistance profiles and genetic characterisation of macrolide resistant isolates of Streptococcus agalactiae. Mem. Inst. Oswaldo Cruz 2011, 106, 119-122. [CrossRef]

21. De Francesco, M.A.; Caracciolo, S.; Gargiulo, F.; Manca, N. Phenotypes, genotypes, serotypes and molecular epidemiology of erythromycin-resistant Streptococcus agalactiae in Italy. Eur. J. Clin. Microbiol. Infect. Dis. 2012, 31, 1741-1747. [CrossRef]

22. Morozumi, M.; Wajima, T.; Kuwata, Y.; Chiba, N.; Sunaoshi, K.; Sugita, K.; Sakata, H.; Iwata, S.; Ubukata, K. Associations between capsular serotype, multilocus sequence type, and macrolide resistance in Streptococcus agalactiae isolates from Japanese infants with invasive infections. Epidemiol. Infect. 2014, 142, 812-819. [CrossRef] [PubMed]

23. Blaschke, A.J.; Pulver, L.S.; Korgenski, E.K.; Savitz, L.A.; Daly, J.A.; Byington, C.L. Clindamycin-resistant group B Streptococcus and failure of intrapartum prophylaxis to prevent early-onset disease. J. Pediatrics 2010, 156, 501-503. [CrossRef] [PubMed]

24. Capanna, F.; Emonet, S.P.; Cherkaoui, A.; Irion, O.; Schrenzel, J.; Martinez de Tejada, B. Antibiotic resistance patterns among group B Streptococcus isolates: Implications for antibiotic prophylaxis for early-onset neonatal sepsis. Swiss Med. Wkly. 2013, 143, w13778. [CrossRef] [PubMed]

25. Capraro, G.A.; Rambin, E.D.; Vanchiere, J.A.; Bocchini, J.A., Jr.; Matthews-Greer, J.M. High rates of inducible clindamycin resistance among prenatal group B streptococcal isolates in one northwest Louisiana academic medical center. J. Clin. Microbiol. 2013, 51, 2469. [CrossRef]

26. Di Renzo, G.C.; Melin, P.; Berardi, A.; Blennow, M.; Carbonell-Estrany, X.; Donzelli, G.P.; Hakansson, S.; Hod, M.; Hughes, R.; Kurtzer, M.; et al. Intrapartum GBS screening and antibiotic prophylaxis: A European consensus conference. J. Matern. Fetal Neonatal Med. 2015, 28, 766-782. [CrossRef]

27. Manning, S.D.; Lewis, M.A.; Springman, A.C.; Lehotzky, E.; Whittam, T.S.; Davies, H.D. Genotypic diversity and serotype distribution of group B streptococcus isolated from women before and after delivery. Clin. Infect. Dis. 2008, 46, 1829-1837. [CrossRef] 
28. Teatero, S.; McGeer, A.; Low, D.E.; Li, A.; Demczuk, W.; Martin, I.; Fittipaldi, N. Characterization of invasive group B streptococcus strains from the greater Toronto area, Canada. J. Clin. Microbiol. 2014, 52, 1441-1447. [CrossRef]

29. Matuschek, E.; Brown, D.F.; Kahlmeter, G. Development of the EUCAST disk diffusion antimicrobial susceptibility testing method and its implementation in routine microbiology laboratories. Clin. Microbiol. Infect. 2014, 20, O255-O266. [CrossRef] 